\title{
Palcos da crítica
}

\section{Maria Helena Serôdio}

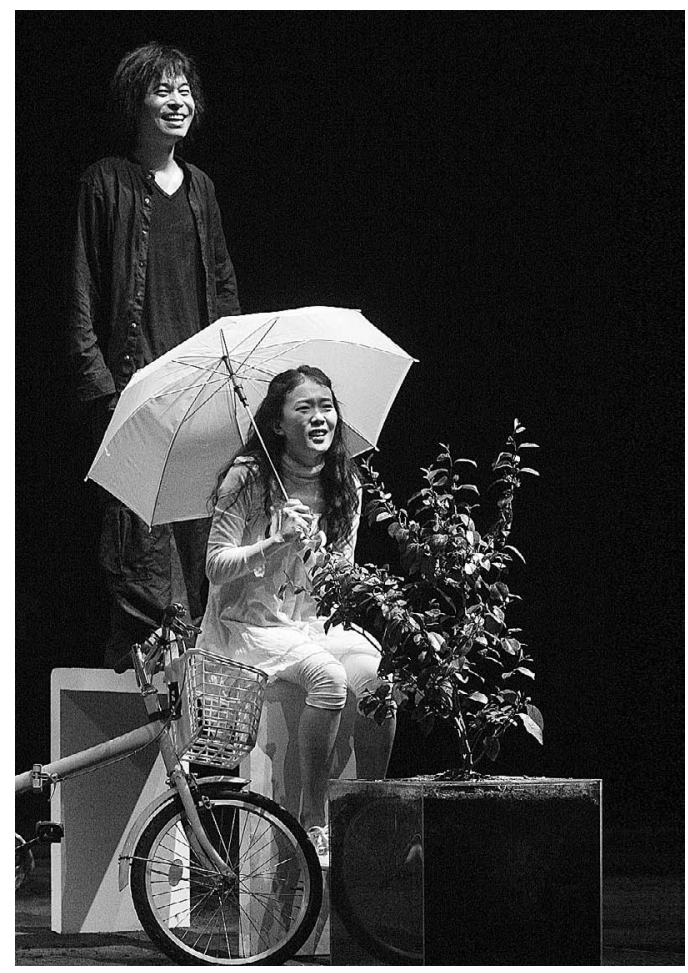

Na sua já longa história, a Associação Internacional de Críticos de Teatro (AICT-IATC), criada em 1956, em Paris, no âmbito da UNESCO, tem promovido, a um nivel verdadeiramente internacional, a actividade crítica nas suas várias vertentes: procura, acima de tudo, diálogos produtivos com as artes do palco (que interroga, analisa e avalia), mas não dispensa a reflexão teórica, o argumentário crítico, a ponderação deontológica, bem como a necessária investigação inter- e multicultural no plano da recepção crítica, privilegiada como é nas relações que estabelece entre profissionais (da crítica e da investigação teatral) em tantos lugares do mundo.

Com cerca de 50 secções nacionais - a que deveremos acrescentar membros individuais em paises onde ainda não foi possivel criar uma secção nacional -, a AICT vem organizando - para além dos seus Congressos de dois em dois anos - simpósios temáticos, conferências, seminários para jovens críticos (estes geralmente no âmbito de Festivais Internacionais), mas participa ainda em júris de festivais, concursos e exposições - bem como outras manifestações de âmbito nacional e internacional em vários paises - oferecendo-se, naturalmente, como espaço privilegiado de contacto e troca de conhecimentos entre profissionais.

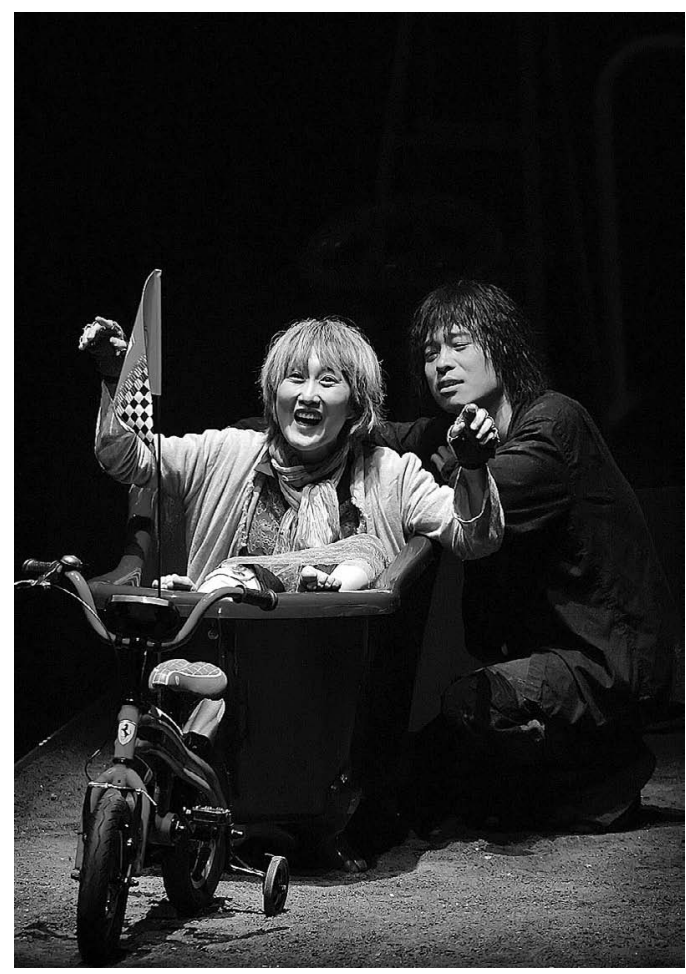

Peer Gynt

de lbsen,

enc. Jung-woong Yang,

LG Art Center

e Yo-hang-ja

(The Travelers),

Seoul, Korea, 2009,

fot. LG Art Center.
Para além de manter a sua página web - www.aictiatc.org - actualizada e rica em informações sobre iniciativas passadas e futuras, a AICT pôs recentemente em prática uma das propostas apresentadas pelo seu actual Presidente - o sul-coreano Yun-Cheol Kim, crítico, autor de vários livros, director da Revista de Teatro Coreano e Professor da Universidade das Artes da Coreia - ao Congresso que o elegeu em 2008 em Sofia, Bulgária: a criação de uma revista semestral online que, em discussão alargada, acabou por receber o nome Critical Stages / Scènes critiques. Encontram-na no endereço www.criticalstages.org e poderão constatar como no seu corpo redactorial estão críticos e estudiosos de vários continentes - Europa, África, Ásia e América (do Norte, Centro e Sul) - e como, neste primeiro número, lançado em Outubro deste ano, contamos com a "presença" de dezasseis países, enquanto nacionalidade de autores ou de realidades recenseadas: África do Sul, Alemanha, Canadá (anglófono e Quebeque), Coreia, EUA, Finlândia, França, Grécia, Hungria, Índia, Israel, Japão, México, Polónia, Portugal e Reino Unido. Sendo uma revista bilingue - que usa o inglês e o francês enquanto línguas oficiais da AICT -, só em artigos um pouco mais longos é que, no início, se apõe um breve resumo na outra língua que não aquela em que o autor escreveu. 

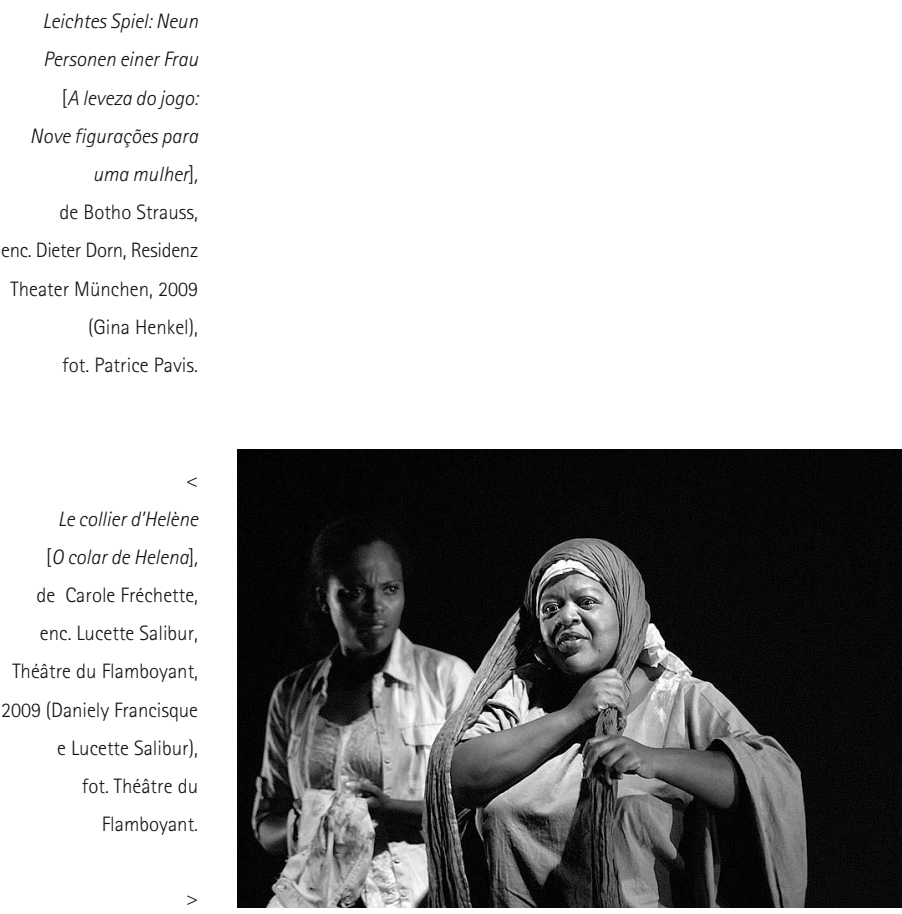

Medea sueña Corinto [Medeia sonha com Corinto],

de Abelardo Estorino Cia Teatral Hubert de Blanck, La Habana, Cuba 2008 (Adria Santana), fot. Jorge Luis Baños.

Trata-se de uma espécie de jogo originariamente inglês ("Confissões", que remonta a 1860) e a que Marcel Proust "responde" a titulo confessional e com espirito lúdico, por volta de 1890. Vem a público só em 1920 e, mais recentemente, tem vindo a ser usado nos media para interpelar criadores e artistas em geral, cruzando, de forma algo aleatória, perguntas sobre a obra, derivas sobre aspirações e autocriticas, mas também indiscrições pessoais e intimas (v. http:/

fr.wikipedia.org/wikil Questionnaire_de_Proust).

${ }^{2} 0$ segundo critico premiado - o teórico, professor e encenado francês Jean-Pierre Sarrazac - será o entrevistado do $n$ 2 de Critical Stages/Scènes critiques, a sair em Abril de
Em formato digital, acedemos a uma barra superior onde se enunciam secções integrando "críticas", "entrevistas" e "artigos", contando ainda este número com uma longa e curiosa entrevista - conduzida pelo jovem crítico norte-americano Randy Gener em formato proustiano ${ }^{1}$ - a Eric Bentley, o primeiro a receber o Prémio Thalia, que a AICT criou para destacar um pensador que tenha marcado de forma indelével o pensamento crítico a nivel internacional ${ }^{2}$. Discutem-se ainda alguns legados artísticos - de Jerzy Grotowski, principalmente, mas também de Eugene lonesco e Augusto Boal -, e em lugar inicial e final alinham-se artigos que reflectem sobre 0 que tem sido a crítica de teatro ao longo da história. Em larga medida, esta reflexão sobre os caminhos da crítica - ou, de forma mais genérica, do comentário - de teatro faz parte de uma das linhas que se procura desenvolver no âmbito da AICT e que prevê a eventual publicação em livro de uma visão histórica por regiões do mundo (com anexo antológico de vozes decisivas nos diversos planos nacionais ao longo da história) e de uma espécie de vade mecum sobre o ensino e a prática da crítica, com base nos programas que vêm sendo seguidos em universidades e escolas superiores em vários paises.

Na secção das entrevistas, registe-se a participação de Rita Martins em conversa com José Maria Vieira Mendes e Marta Carreiras, e da Coreia vem o outro entrevistado: o celebrado dramaturgo e encenador Yun-Taek Lee. Entre os artigos, chamaria a atenção para a reflexão argumentada e iconografada - de Patrice Pavis sobre 0 ponto de encontro entre o teatro e a filosofia, e na secção das críticas a espectáculos, veja-se a riqueza de perspectivas que nos chega pelas reflexões analíticas de Kyoung-hee Kwon, Vivian Martínez Tabares, Irène Sadowska Guillon, Tomasz Miłkowski, Robert Greig, Alvina Ruprecht, Patrice Pavis e Savas Patsalidis.

Em "lugares" cardinais - de exórdio e coda - desta publicação, encontramos refracções do que se falou num
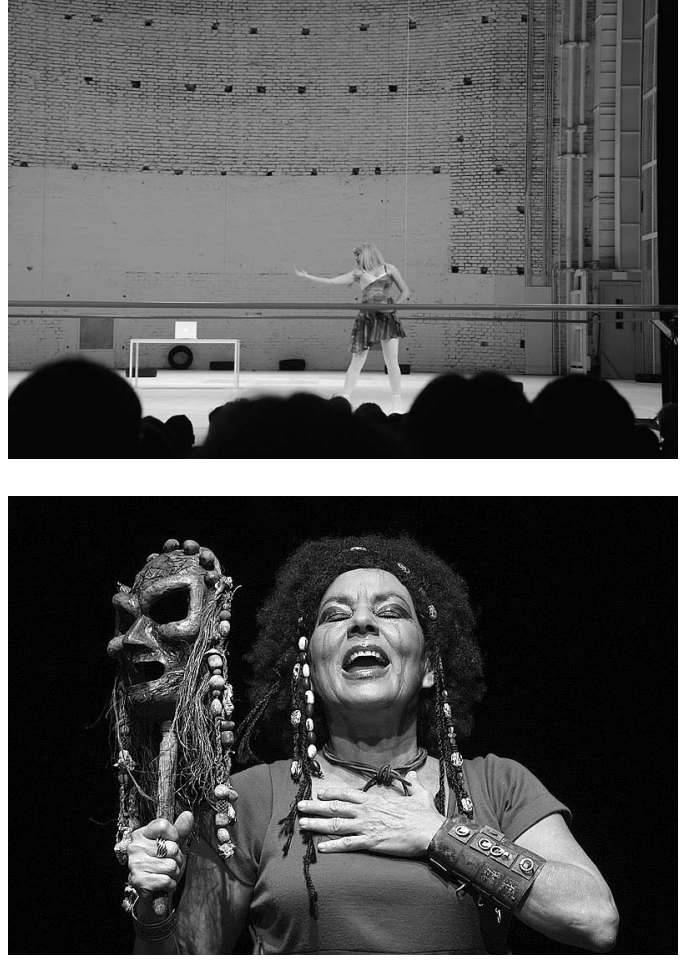

simpósio organizado por Don Rubin em Toronto (Canadá) em Outubro de 2008, incluindo curiosas deambulações pelo tratado apaixonante de Bharata em sânscrito Natyashastra - de que falou com saber e sentido analítico Ravi Chaturvedi. Como nos elucida o crítico, professor e investigador indiano, o tratado foi escrito mais ou menos por volta do séc. IV a.C., pouco depois, parece, da Poética de Aristóteles, e inclui observações sobre todos os aspectos relativos ao teatro, desde teorias estéticas a práticas histriónicas, incluindo ainda o trabalho técnico de palco e problemas de gestão. De resto, o seu próprio título reflecte esta metodologia sistemática uma vez que "Natya" significa teatro e "shastra" significa "ciência". 0 que tem sido menos divulgado e trabalhado desse tratado são justamente as formas de recepção e crítica, de que aqui nos fala, com um sentido de genuino deleite - e percebese bem porquê -, o autor do artigo.

Na secção final - "Críticos sobre a crítica" - John Elsom (Presidente Honorário da AICT), Manabu Noda e Yun-Cheol Kim dão-nos preciosas informações sobre as "origens" da crítica de teatro, respectivamente, na Inglaterra (do séc. XVIII), no Japão (desde meados do séc. XI) e na Coreia (há apenas 100 anos), provando como a crítica foi sendo um pólo decisivo de configuração da própria arte do teatro, dialogando a favor de formas e temáticas relevantes e ajudando a firmar tradições, preparar públicos e registar para a História o que se foi fazendo em palco. $E$, prosseguindo esse que foi sendo o sentido primeiro e incontornável do comentário e crítica de teatro ao longo da história, aqui está a revista que a Associação Internacional de Críticos de Teatro concebeu para cumprir o que hoje se espera deles - críticos - e que as novas tecnologias permitem que chegue a qualquer hora e gratuitamente a todos os que se interessam por teatro $e$ as artes do palco, em geral. Mas que aguarda, dos críticos e leitores em geral, sugestões, lembretes e propostas para melhor cumprir essa missão. 